\title{
Enhanced thermal stability and mechanical properties of nitrogen deficient titanium aluminum nitride (Ti0.54Al0.46Ny) thin films by tuning the applied negative bias voltage
}

Katherine Calamba, Isabella Schramm, M. P. J ohansson J oesaar, J . Ghanbaja, J . F. Pierson, F. Mucklich and Magnus Odén

The self-archived postprint version of this journal article is available at Linköping University Institutional Repository (DiVA):

http:/ / urn.kb.se/ resolve?urn=urn:nbn:se:liu:diva-140514

N.B.: When citing this work, cite the original publication.

Calamba, K., Schramm, I., J ohansson J oesaar, M. P., Ghanbaja, J ., Pierson, J . F., Mucklich, F., Odén, M., (2017), Enhanced thermal stability and mechanical properties of nitrogen deficient titanium aluminum nitride (Ti0.54Al0.46Ny) thin films by tuning the applied negative bias voltage, J ournal of Applied Physics, 122(6). https:// doi.org/ 10.1063/ 1.4986350

Original publication available at:

https:/ / doi.org/ 10.1063/ 1.4986350

Copyright: AIP Publishing

http:// www.aip.org/ 


\title{
Enhanced thermal stability and mechanical properties of nitrogen deficient titanium aluminum nitride $\left(\mathrm{Ti}_{0.54} \mathrm{Al}_{0.46} \mathrm{~N}_{\mathrm{y}}\right)$ thin films by tuning the applied negative bias voltage
}

\author{
K.M. Calamba, ${ }^{1,2, a), ~ I . C . ~ S c h r a m m ~}{ }^{1,3}$, M.P. Johansson Jõesaar ${ }^{1,4}$, J. Ghanbaja², J.F. \\ Pierson $^{2}$, F. Mücklich ${ }^{3}$, and M. Odén ${ }^{1}$ \\ ${ }^{1}$ Nanostructured Materials, Department of Physics, Chemistry and Biology (IFM), Linköping \\ University, Linköping, SE 58183, Sweden \\ ${ }^{2}$ Institut Jean Lamour (UMR CNRS 7198), Université de Lorraine, Nancy, 54011, France \\ ${ }^{3}$ Functional Materials, Department Materials Science, Saarland University, Saarbrucken, \\ 66041, Germany \\ ${ }^{4}$ SECO Tools AB, Fagersta, SE-73782, Sweden
}

Aspects on the phase stability and mechanical properties of nitrogen deficient $\left(\mathrm{Ti}_{0.54} \mathrm{Al}_{0.46}\right) \mathrm{N}_{\mathrm{y}}$ alloys were investigated. Solid solution alloys of (Ti,Al)N were grown by cathodic arc deposition. The kinetic energy of the impinging ions was altered by varying the substrate bias voltage from $-30 \mathrm{~V}$ to $-80 \mathrm{~V}$. Films deposited with a high bias value of $-80 \mathrm{~V}$ showed larger lattice parameter, finer columnar structure, and higher compressive residual stress resulting in higher hardness than films biased at $-30 \mathrm{~V}$ when comparing their as-deposited states. At elevated temperatures, the presence of nitrogen vacancies and point defects (anti-sites and self-interstitials generated by the ion-bombardment during coating deposition) in $\left(\mathrm{Ti}_{0.54} \mathrm{Al}_{0.46}\right) \mathrm{N}_{0.87}$ influence the driving force for phase separation. Highly biased nitrogen deficient films have point defects with higher stability during annealing, which cause a delay of the release of the stored lattice strain energy and then accelerates the decomposition tendencies to thermodynamically stable $c$-TiN and $w$-AlN. Low biased nitrogen deficient films have retarded phase transformation to $w$-AlN, which results to the prolongment of age hardening effect up to $1100{ }^{\circ} \mathrm{C}$, i.e. the highest reported temperature for Ti-Al-N material system. Our study points out the role of vacancies and point defects in engineering thin films with enhanced thermal stability and mechanical properties for high temperature hard coating applications. 


\section{INTRODUCTION}

Investigation on the thermal stability of transition metal nitride thin films is of importance because it is a key factor in determining their distinctive physical properties, e.g. hardness, wear resistance, and electrical properties. ${ }^{1-3}$ Among the metal nitrides, titanium aluminum nitride (Ti,Al)N based coating has remained as an outstanding material system partly due to its excellent high temperature resistance combined with an age hardening behavior resulting in good wear resistance. ${ }^{2,4}$ The latter is based on a spinodal decomposition of the metastable cubic $(c)$ solid solution $c$-(Ti,Al) $\mathrm{N}^{5}$ into isostructurally coherent $c$-TiN and $c$-AlN rich domains at elevated temperatures. ${ }^{6-7}$ The latter generate a hardness enhancement and hence improved mechanical properties of the $c-(\mathrm{Ti}, \mathrm{Al}) \mathrm{N}$ due to fluctuating strain fields ${ }^{8}$ caused by coherency strains ${ }^{9}$ and elastic stiffness differences ${ }^{10-11}$ that obstructs dislocation motion. At even higher thermal loads, however, the $c$-AlN transform into its most stable phase, i.e. wurtzite $\mathrm{w}$-AlN, ${ }^{12}$ which is detrimental for the mechanical properties of the coating. ${ }^{13}$ Suppressing or delaying the $w$-AlN formation is therefore expected to enhance the thermal stability and the mechanical properties of (Ti,Al)N thin film and extend its operational envelope to higher temperatures.

Ab initio calculations on $c-\mathrm{Ti}_{1-\mathrm{x}} \mathrm{Al}_{\mathrm{x}} \mathrm{N}_{1-\mathrm{y}}(0 \leq \mathrm{x}, \mathrm{y} \leq 1)$ have shown that nitrogen vacancies $\left(\mathrm{V}_{\mathrm{N}}\right)$ has significant effect on the driving force for decomposition and the preferred decomposition direction. ${ }^{14}$ This was experimentally confirmed by Schramm et al., ${ }^{15}$ where the presence of $\mathrm{V}_{\mathrm{N}}$ enhanced the phase stability, i.e. delaying the onset of decomposition of cathodic arc evaporated $(\mathrm{Ti}, \mathrm{Al}) \mathrm{N}_{\mathrm{y}}(\mathrm{y}<1)$. It was shown that the onset of $w$-AlN phase transformation in $\left(\mathrm{Ti}_{0.52} \mathrm{Al}_{0.48}\right) \mathrm{N}_{0.87}$ occurred at about $1200{ }^{\circ} \mathrm{C},{ }^{15}$ which is about $300{ }^{\circ} \mathrm{C}$ higher than what typically is reported for stoichiometric $\left(\mathrm{Ti}_{0.5} \mathrm{Al}_{0.5}\right) \mathrm{N}$ thin films. ${ }^{16-17}$ Primary decomposition occurs on the metal sublattice and To Baben et al. ${ }^{18}$ also reports an improved thermal stability of close to stoichiometric (Ti,Al) $\mathrm{N}_{\mathrm{y}}(\mathrm{y} \approx 1)$ as compared to over- 
stoichiometric $(\mathrm{Ti}, \mathrm{Al}) \mathrm{N}_{\mathrm{y}}(\mathrm{y}>1)$. The faster decomposition in over-stoichiometric $(\mathrm{y}>1)$ films is attributed to an enhanced diffusivity in the presence of metal vacancies. It has to be noted that in addition to vacancies, structural modifications in the film such as lattice strain also play a decisive role in determining its thermal stability since it is correlated to the energetic balance during the decomposition process of cubic ternary transition metal nitride. ${ }^{19-20}$ Another approach to control the structure and properties of coatings is through the substrate bias condition. ${ }^{21-23}$ It is well known that the bias determines the kinetic energy of the ions bombarding the growing film. In this context, cathodic arc deposition is advantageous since its plasma typically comprises a high degree of ionized metal vapor and therefore tuning the negative bias is an effective mean to change the arrival energy of the condensing species $^{24}$ and hence also the microstructure and its point defect density (interstitials and anti-sites). ${ }^{25}$

In this study, the influence of such point defects in combination with nitrogen vacancies on the thermal stability of cathodic arc deposited $\mathrm{Ti}_{0.54} \mathrm{Al}_{0.46} \mathrm{~N}_{0.87}$ thin films were investigated. The Ti/Al ratio and amount of nitrogen vacancies was fixed at a level found by Schramm et al. ${ }^{15}$ to yield substantially improved phase stability. The substrate bias voltage was varied from $-30 \mathrm{~V}$ to $-80 \mathrm{~V}$ in reference to the anode potential. At elevated temperatures, high biased films presented an enhanced phase separation while low biased films showed the highest phase stability. It is noteworthy that the age hardening effect of these coatings is retained to a temperature higher than ever before reported for Ti-Al-N materials. This paper also highlights the interplay between nitrogen vacancies and microstructure on transformation kinetics, which is of relevance for the understanding of metastable transition metal nitrides' thermal stability and mechanical properties. 


\section{MATERIAL AND METHODS}

$\left(\operatorname{Ti}_{1-x} A_{x}\right) N_{y}$ films were deposited using an industrial scale (Metaplas MZR-323) reactive cathodic arc deposition system. A powder metallurgical manufactured $\operatorname{Ti}_{0.45} \mathrm{Al}_{0.55}$ cathode with a diameter of $100 \mathrm{~mm}$ was used as target. Fe foils (Goodfellow Cambridge Ltd FE000400) and polished cemented carbide (WC-Co) inserts (12 wt.\% Co, ISO SNUN120408) were used as substrates. The substrates were cleaned in an alkaline solution prior to inserting the substrates in the deposition chamber. In the chamber they were mounted on a rotating cylinder fixture (3 rpm) facing the cathode. Pure $\mathrm{N}_{2}$ was used to obtain $\left(\mathrm{Ti}_{1}\right.$ $\left.{ }_{x} \mathrm{Al}_{\mathrm{x}}\right) \mathrm{N}$ reference samples with compositions close to stoichiometric value ${ }^{15}$ while an atmosphere mixture of $40 \% \mathrm{~N}_{2} /\left(\mathrm{Ar}+\mathrm{N}_{2}\right)$ was used to synthesize the nitrogen deficient coatings. During deposition, a total gas pressure of 2 Pa was used for both conditions. The flow rates of $\mathrm{N}_{2}$ and Ar were set to 120 sccm and 180 sccm, respectively to obtain the $40 \%$ $\mathrm{N}_{2} /\left(\mathrm{Ar}+\mathrm{N}_{2}\right)$ mixture and the gasses were introduced through pipes positioned vertically in the chamber. An arc current of 13.7 A was required to achieve stable deposition conditions, which resulted in plasma heating of the substrates. To improve coating adhesion, additional heating was supplied by a heater positioned on the chamber wall. Collectively this resulted in a deposition temperature of $550^{\circ} \mathrm{C}$. Thin films were grown to a thickness of about $3 \mu \mathrm{m}$ with a deposition rate of $250 \mathrm{~nm} / \mathrm{min}$. All deposition conditions were kept constant between depositions for each deposition atmosphere, except for the substrate bias voltage that was set to: $-30 \mathrm{~V},-43 \mathrm{~V},-55 \mathrm{~V},-68 \mathrm{~V}$, or $-80 \mathrm{~V}$ for the different coatings.

A differential scanning calorimeter (DSC, Netsch STA 449C) was used to examine the thermal response of the as-deposited films. Powder samples were used in the analysis and extracted from the coatings deposited on the Fe foils. Powder samples were obtained by first thinning of the Fe foil by mechanical grinding its backside and then dissolving it in concentrated (37\%) $\mathrm{HCl}^{26}$ DSC measurements were performed with two heating cycles, in 
which the second cycle was used as baseline correction. The sample mass used per run was $30 \mathrm{mg}$. The powder samples were initially outgassed for 1 hour at $250{ }^{\circ} \mathrm{C}$ after which the measurement started by heating up the sample to $1400^{\circ} \mathrm{C}$ in $50 \mathrm{sccm}$ flow of Ar. The heating and cooling rate was kept constant at $20^{\circ} \mathrm{C} / \mathrm{min}$.

X-ray diffractograms of the powdered samples and coatings on substrates recorded with a PANalytical X'Pert PRO MRD diffractometer and were used for phase analysis. Residual stress measurements of the coatings on substrates were obtained using a PANalytical Empyrean diffractometer. The $\sin ^{2} \psi$ method was used to determine the strain state in the coating using the 422 diffraction line. The elastic constants used to convert the strain measurements to stress are: $E=460 \mathrm{GPa}$ and $v=0.20$, obtained from $a b$ initio calculations. ${ }^{10}$ All x-ray diffractometry measurements were performed using $\mathrm{Cu} \mathrm{K}_{\alpha}$ radiation.

Isothermal annealing of the thin films deposited on the WC-Co substrates were performed in a tube furnace under vacuum with a base pressure of $7 \times 10^{-4} \mathrm{~Pa}$. The samples were held for $15 \mathrm{~min}$ at the maximum temperature of either $800{ }^{\circ} \mathrm{C}, 900{ }^{\circ} \mathrm{C}, 1000{ }^{\circ} \mathrm{C}, 1100$ ${ }^{\circ} \mathrm{C}$, or $1200{ }^{\circ} \mathrm{C}$. The heating and cooling rates were set to $20^{\circ} \mathrm{C} / \mathrm{min}$.

Morphological and microstructural characterizations of the thin films were performed using a scanning electron microscope (SEM) (FEI Helios nanolab 600), scanning transmission electron microscope (STEM) and energy-filtered analytical transmission electron microscopes (EFTEM) (JEOL ARM 200 Cold FEG), and analytical transmission electron microscope (TEM) (Fei Tecnai $G^{2}$ TF 20 UT). The analytical TEM was used to obtain the selected area electron diffraction (SAED) images. A focus ion beam (FIB) integrated in the SEM was used for producing cross section cuts. Both TEMs were operated at an acceleration voltage of $200 \mathrm{kV}$. Cross sectional TEM samples were prepared through mechanical grinding and polishing, followed by sputter etching (Gatan 691 precision ion polishing system) until the sample was electron transparent $(<100 \mathrm{~nm})$. 
The 3D chemical composition was obtained from a local electrode atom probe (Cameca LEAP 3000 X HR) operated in laser mode with a wavelength of $532 \mathrm{~nm}$, a pulse frequency of $200 \mathrm{kHz}$ and a pulse energy of $0.5 \mathrm{~nJ}$. Evaporation rate was set to 5 atoms per 1000 laser pulses, and sample was set to a ground temperature of $60 \mathrm{~K}$. Data reconstruction was performed in the IVAS package (version 3.6.8, Cameca) using the voltage mode. Reconstruction parameters were obtained using Kingham curves ${ }^{27}$ and SEM images of the tip before and after run, where an evaporation field of $40 \mathrm{~V}$ per $\mathrm{nm}$, and a field factor between 3.5 to 3.8 were obtained. Atom probe tomography (APT) tips were produced using the FIB equipment via the standard lift out technique. ${ }^{28}$

The hardness values of the coatings were measured using UMIS nanoindenter equipped with a Berkovich diamond tip. Depth-sensing indentation was performed on polished tapered cross-sections of the coatings using a maximum load of $50 \mathrm{mN}$. The indentation depths for this amount of load were around $250 \mathrm{~nm}$, which is less than $10 \%$ of the film's thickness. The average hardness values were extracted from the load-displacement curves using the Oliver and Pharr method. ${ }^{29}$ At least 30 indents for were used for each samples and fused silica was used as reference to compute the contact area of the tip versus penetration depth.

\section{RESULTS}

The chemical composition of as-deposited $\left(\mathrm{Ti}_{1-\mathrm{x}} \mathrm{Al}_{\mathrm{x}}\right) \mathrm{N}_{\mathrm{y}}$ films deposited in an atmosphere mixture of $40 \% \mathrm{~N}_{2} /\left(\mathrm{Ar}+\mathrm{N}_{2}\right)$ at different negative bias voltages is shown in Table I. Composition values were obtained via APT and only the main elements ( $\mathrm{Al}, \mathrm{Ti}$, and $\mathrm{N}$ ) were used for the values of $\mathrm{x}=\mathrm{Al} /(\mathrm{Al}+\mathrm{Ti})$ and $\mathrm{y}=\mathrm{N} /(\mathrm{Al}+\mathrm{Ti})$. These films are referred as the nitrogen deficient samples. The total content of impurity elements such as $\mathrm{O}, \mathrm{C}$ and Ar is less than 0.5 at. \%. Results show that the chemical composition of the thin films is not altered with the variation of the bias voltage. 
Table I. Composition of $\left(\mathrm{Ti}_{1-\mathrm{x}} \mathrm{Al}_{\mathrm{x}}\right) \mathrm{N}_{\mathrm{y}}$ films in an atmosphere mixture of $40 \% \mathrm{~N}_{2} /\left(\mathrm{Ar}+\mathrm{N}_{2}\right)$ at different negative bias voltages.

\begin{tabular}{|c|c|c|}
\hline Bias Voltage & $\mathrm{x}=\mathrm{Al} /(\mathrm{Al}+\mathrm{Ti})$ & $\mathrm{y}=\mathrm{N} /(\mathrm{Al}+\mathrm{Ti})$ \\
\hline$-30 \mathrm{~V}$ & $0.46 \pm 0.01$ & $0.87 \pm 0.02$ \\
\hline$-43 \mathrm{~V}$ & $0.46 \pm 0.01$ & $0.87 \pm 0.01$ \\
\hline$-55 \mathrm{~V}$ & $0.46 \pm 0.02$ & $0.87 \pm 0.03$ \\
\hline$-68 \mathrm{~V}$ & $0.46 \pm 0.01$ & $0.86 \pm 0.01$ \\
\hline$-80 \mathrm{~V}$ & $0.46 \pm 0.01$ & $0.87 \pm 0.02$ \\
\hline
\end{tabular}

The X-ray diffraction patterns of the nitrogen deficient $\left(\mathrm{Ti}_{0.54} \mathrm{Al}_{0.46}\right) \mathrm{N}_{0.87}$ films at different bias voltage are shown in Figure $1 \mathrm{a}$. The XRD peaks at $37.16^{\circ}, 43.15^{\circ}$, and $62.66^{\circ}$ correspond to the $c-(\mathrm{Ti}, \mathrm{Al}) \mathrm{N} 111,200$, and 220 diffraction peaks, respectively. The other peaks originate from the WC-Co substrate. XRD reveals that the bias voltage does not alter the phase composition and all as-deposited $\left(\mathrm{Ti}_{0.54} \mathrm{Al}_{0.46}\right) \mathrm{N}_{0.87}$ thin films have of a single phase with cubic NaCl-structure. Diffractograms show that an increase of the bias voltage leads to a small shift to lower $2 \theta$ values. Peak shifts are mainly caused by strain or by compositional changes. ${ }^{30}$ APT measurements show that the elemental compositions of the films are not altered by bias voltage thus the observed shifts are attributed to changes in compressive stress. The measured compressive residual stresses of the films biased at $-30 \mathrm{~V}$, $-55 \mathrm{~V}$, and $-80 \mathrm{~V}$ are $-2.8 \pm 0.4 \mathrm{GPa},-2.9 \pm 0.8 \mathrm{GPa}$, and $-5.6 \pm 1 \mathrm{GPa}$, respectively. The increase in compressive stress is accompanied with line broadening, which indicates increasing microstrains. The high compressive residual stress in the as-deposited films with increased negative bias voltage has been observed for several materials synthesized by cathodic arc deposition. ${ }^{21,23,31}$ In addition, a clear decrease of the 200 peak intensity and a change of preferred orientation to (111) and (220) are observed as a consequence of 
increasing the negative substrate bias voltage. The X-ray diffractograms of the $\left(\mathrm{Ti}_{0.54} \mathrm{Al}_{0.46}\right) \mathrm{N}$ reference samples (Figure 1b) also show that they also crystallize in the cubic structure in the as-deposited state (Figure 1b). These films also exhibit peak shifts and line broadening when the applied bias voltage is increased, similar with the nitrogen deficient samples. The relative intensity of the 220 peak is more pronounced with high biasing condition. The peak intensity ratio $\mathrm{I}^{111} / \mathrm{I}^{200}$ of the nitrogen deficient coatings is higher as compared to the reference samples.
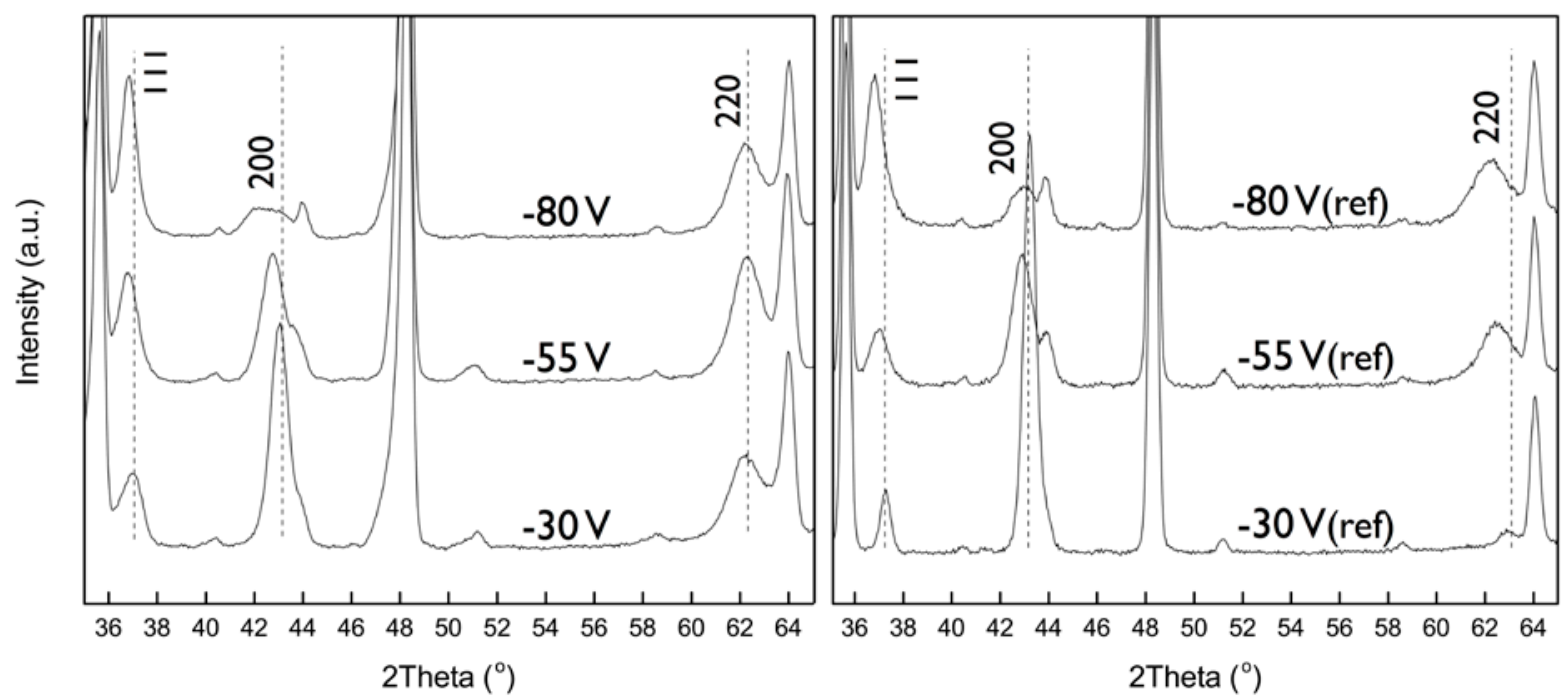

Figure 1. X-ray diffractograms of as-deposited $\left(\mathrm{Ti}_{0.54} \mathrm{Al}_{0.46}\right) \mathrm{N}_{\mathrm{y}}$ (a) nitrogen deficient and (b) reference coatings at different negative bias voltages. The unmarked peaks originate from the WC-Co substrate.

The surface morphologies of the as-deposited $\left(\mathrm{Ti}_{0.54} \mathrm{Al}_{0.46}\right) \mathrm{N}_{0.87}$ films with two different bias voltages $(-30 \mathrm{~V}$ and $-80 \mathrm{~V})$ are presented in Figure 2a and 2b. SEM micrographs reveal that macroparticle density and diameter decrease with increasing biased voltage resulting in smoother surfaces. The corresponding microstructures of the films biased at $-30 \mathrm{~V}$ and $-80 \mathrm{~V}$, are shown in Figure 2c and 2d, respectively. Cross sectional TEM micrographs show that highly biased films have finer columnar structure. The sample biased at $-80 \mathrm{~V}$ has a column width of $0.21 \pm 0.04 \mu \mathrm{m}$ while that biased at $-30 \mathrm{~V}$ has a width of 0.57 $\pm 0.12 \mu \mathrm{m}$. The measured column widths are typical for (Ti,Al)N films deposited via arc 
technique and their decrease with increasing bias has been also observed in previously. ${ }^{32-33}$ The SAED patterns of the coatings biased at $-30 \mathrm{~V}$ and $-80 \mathrm{~V}$ confirm that the films all have cubic structure in the as deposited state, in agreement with the XRD results.

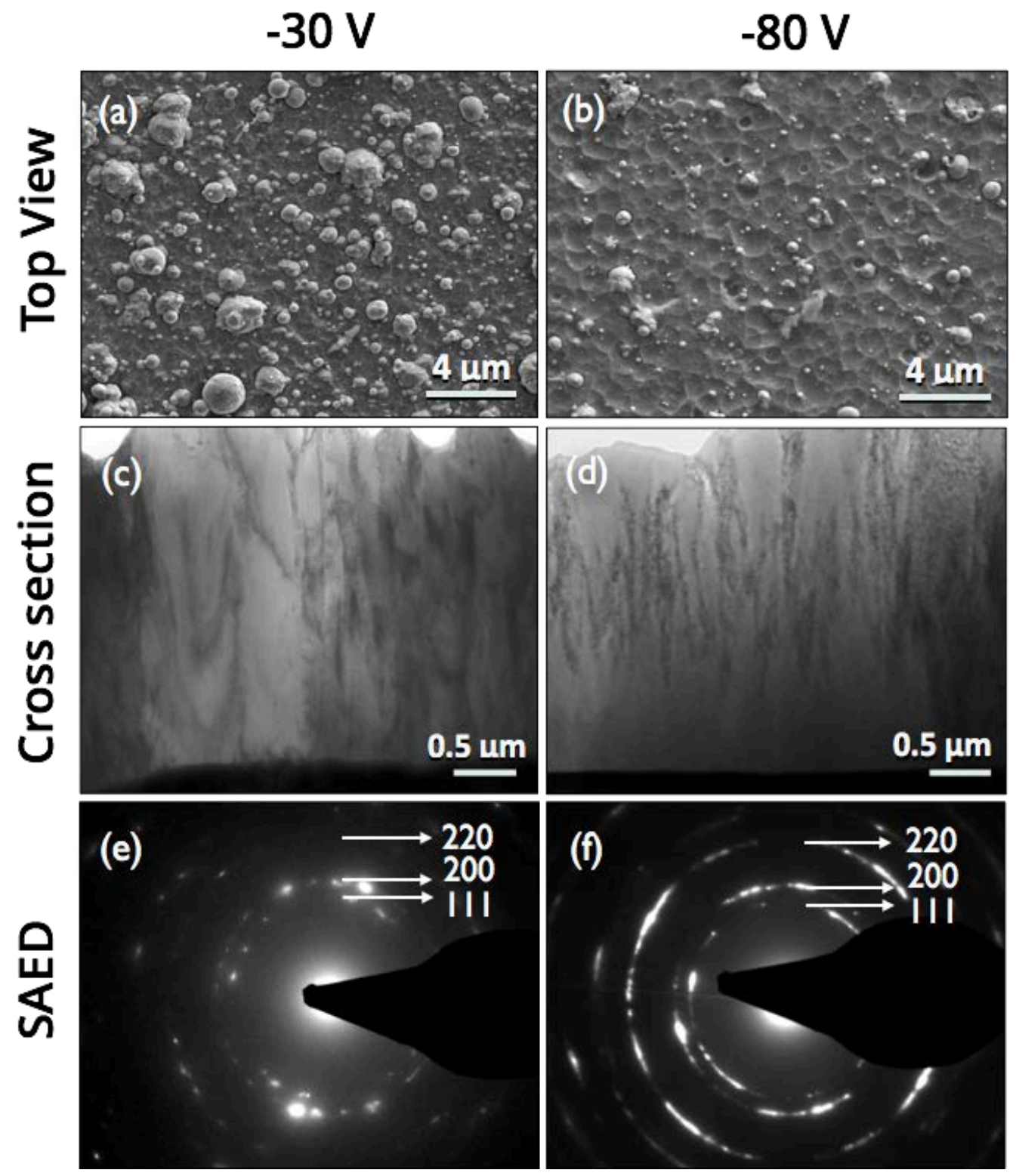

Figure 2. Top-view SEM micrographs of as-deposited $\left(\mathrm{Ti}_{0.54} \mathrm{Al}_{0.46}\right) \mathrm{N}_{0.87}$ films with negative bias voltages of (a) $-30 \mathrm{~V}$ and (b) $-80 \mathrm{~V}$, the cross-sectional TEM images of (c) $-30 \mathrm{~V}$ and (d) $-80 \mathrm{~V}$, and SAED of (e) $-30 \mathrm{~V}$ and (f) $-80 \mathrm{~V}$.

The heat flow responses of $\left(\mathrm{Ti}_{0.54} \mathrm{Al}_{0.46}\right) \mathrm{N}_{\mathrm{y}}$ samples synthesized at different bias voltages were evaluated by DSC as shown in Figure 3. The $\left(\mathrm{Ti}_{0.54} \mathrm{Al}_{0.46}\right) \mathrm{N}_{0.87}$ coating biased at $-30 \mathrm{~V}$ has a broad peak $\left(\mathrm{T}_{1}\right)$ at $900{ }^{\circ} \mathrm{C}$ (in $600{ }^{\circ} \mathrm{C}$ to $1100{ }^{\circ} \mathrm{C}$ range) while the sample biased at $-80 \mathrm{~V}$ has peak at $800{ }^{\circ} \mathrm{C}$ (in $500{ }^{\circ} \mathrm{C}$ to $1000{ }^{\circ} \mathrm{C}$ range). These peaks correspond to 
several exothermic reactions, including recovery processes of lattice point defect complexes at different activation energies and phase separation via spinodal decomposition of $c$ (Ti,Al)N. ${ }^{34-35}$ The $\left(\mathrm{Ti}_{0.54} \mathrm{Al}_{0.46}\right) \mathrm{N}$ reference samples have resolved the $\mathrm{T}_{2}$ peak corresponding to spinodal decomposition. ${ }^{35-36}$ The $\left(\mathrm{Ti}_{0.54} \mathrm{Al}_{0.46}\right) \mathrm{N}$ reference samples biased at $-30 \mathrm{~V}$ and -80 $\mathrm{V}$ and the nitrogen deficient samples biased at $-80 \mathrm{~V}$ show another peak $\left(\mathrm{T}_{3}\right)$ at around 1200 ${ }^{\circ} \mathrm{C}$ corresponding to the transformation of the $c$-AlN into $w$-AlN. This peak is not clearly observed in the nitrogen deficient sample biased at $-30 \mathrm{~V}$ and is expected to occur at higher temperature starting from $1200{ }^{\circ} \mathrm{C}$, where a weak peak is observed. The $\mathrm{T}_{1}$ to $\mathrm{T}_{3}$ peaks are labeled in reference to the $\mathrm{XRD}$ result shown in Figure 4. The peak at $1100{ }^{\circ} \mathrm{C}$ is an instrumental artifact caused by a phase transition in the furnace. The thermal response of the coatings reveals that highly biased nitrogen deficient samples have transformed to $w$-AlN at earlier temperature in comparison to sample grown at lower bias voltage. There is no significant difference on the critical temperatures $\left(T_{1}\right.$ to $\left.T_{3}\right)$ for phase transformation between the reference samples with different applied negative bias, similar to what was previously reported. ${ }^{8}$

$$
\mathrm{T}_{1} \text { : recovery processes } \quad \mathrm{T}_{2} \text { : spinodal decomposition } \quad \mathrm{T}_{3} \text { : cubic-AIN } \rightarrow \text { hex-AIN }
$$

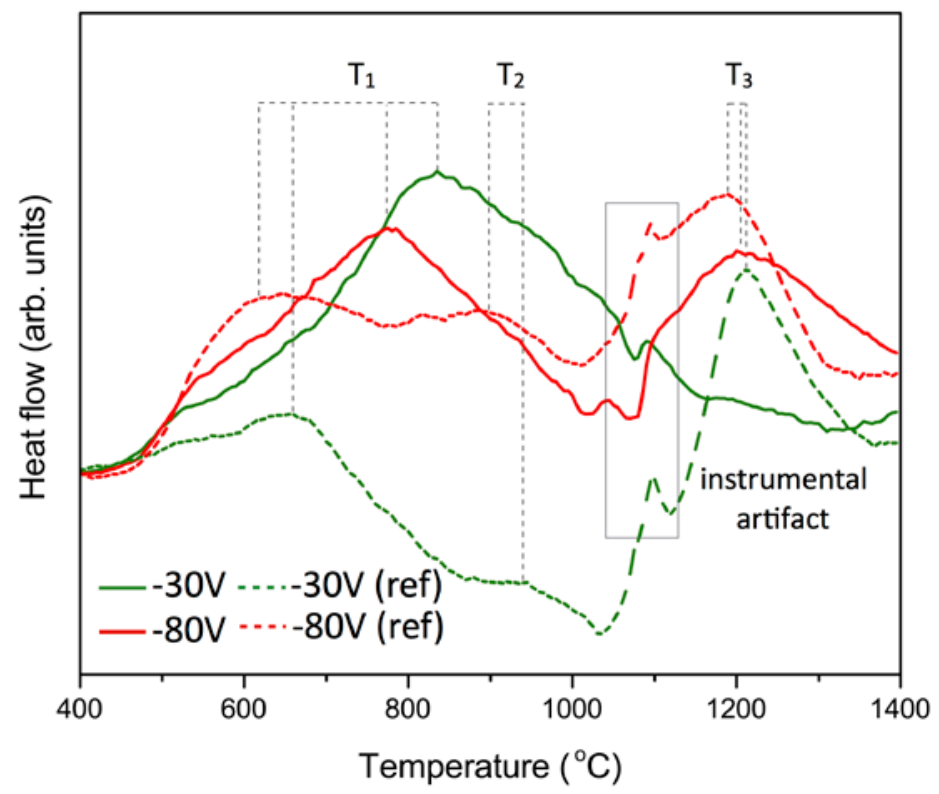

Figure 3. Exothermal response of $\left(\mathrm{Ti}_{0.54} \mathrm{Al}_{0.46}\right) \mathrm{N}_{0.87}$ (solid line) and reference coatings (dashed line) at applied bias voltages of $-30 \mathrm{~V}$ (green) and -80 V (red). 


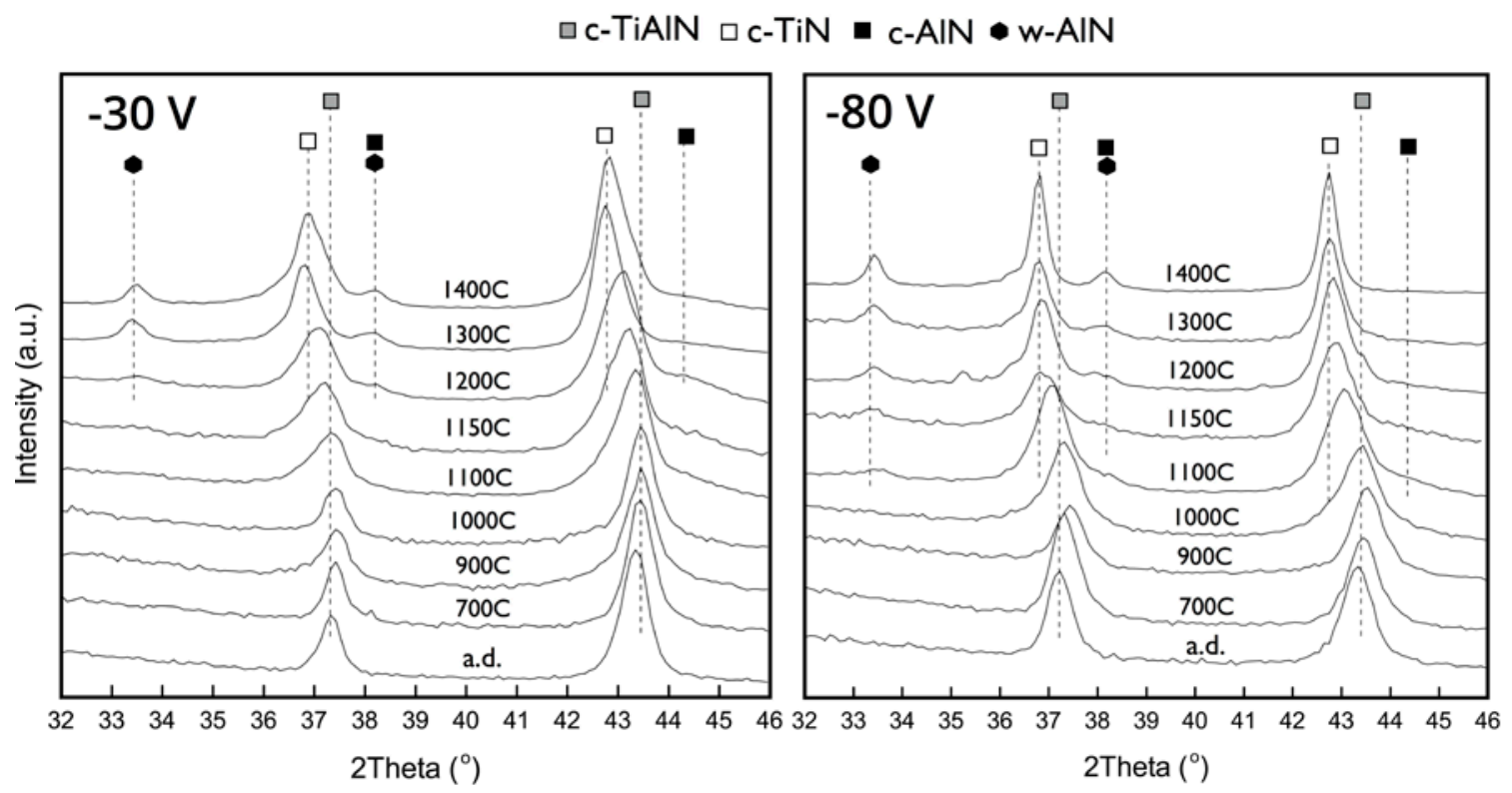

Figure 4. X-ray diffractograms of $\left(\mathrm{Ti}_{0.54} \mathrm{Al}_{0.46}\right) \mathrm{N}_{0.87}$ biased at $-30 \mathrm{~V}$ and $-80 \mathrm{~V}$ after different annealing temperatures.

The as-deposited $\left(\mathrm{Ti}_{0.54} \mathrm{Al}_{0.46}\right) \mathrm{N}_{0.87}$ films were annealed at different temperatures to examine their phase transformation at elevated temperatures. Figure 4 shows their $x$-ray diffractograms measured at room temperature after annealing. The sample biased at $-30 \mathrm{~V}$ presents similar diffractograms in its as-deposited state and after annealing at $1000{ }^{\circ} \mathrm{C}$. This indicates that the material still consists primarily of a solid solution of $c$-( $\mathrm{Ti}, \mathrm{Al}) \mathrm{N}$, only a slight shift to higher angles takes place between 700 and $1000{ }^{\circ} \mathrm{C}$ due to crystal recovery processes that cause stress relaxation. ${ }^{13}$ The recovery is due to the rearrangement of defects and not due to recrystallization ${ }^{25}$ since there has been no change in texture even at elevated temperatures. The $c$-(Ti,Al)N peaks broaden above $1000{ }^{\circ} \mathrm{C}$, indicating formation of $c$-AlN domains and Ti-enriched $c$-(Ti,Al)N domains via spinodal decomposition. ${ }^{7}$ Well resolved diffraction peaks from both phases is observed at $120{ }^{\circ} \mathrm{C}$. Further annealing causes the $c$ AlN peaks to vanish while the $w$-AlN peaks increase in intensity since metastable $c$-AlN transforms to its most stable form at high thermal loadings. ${ }^{12}$ The sample biased at $-80 \mathrm{~V}$ exhibits peak shifting to higher angles between 700 and $900{ }^{\circ} \mathrm{C}$ (due to crystal recovery processes) and peak broadening at $1000{ }^{\circ} \mathrm{C}$ (due to spinodal decomposition). The peak corresponding to $w$-AlN starts to appear at $1100{ }^{\circ} \mathrm{C}$ and becomes more distinct at higher 
temperatures. A similar trend is observed between samples biased at $-30 \mathrm{~V}$ and $-80 \mathrm{~V}$ but the later exhibits phase transformation at earlier temperatures.

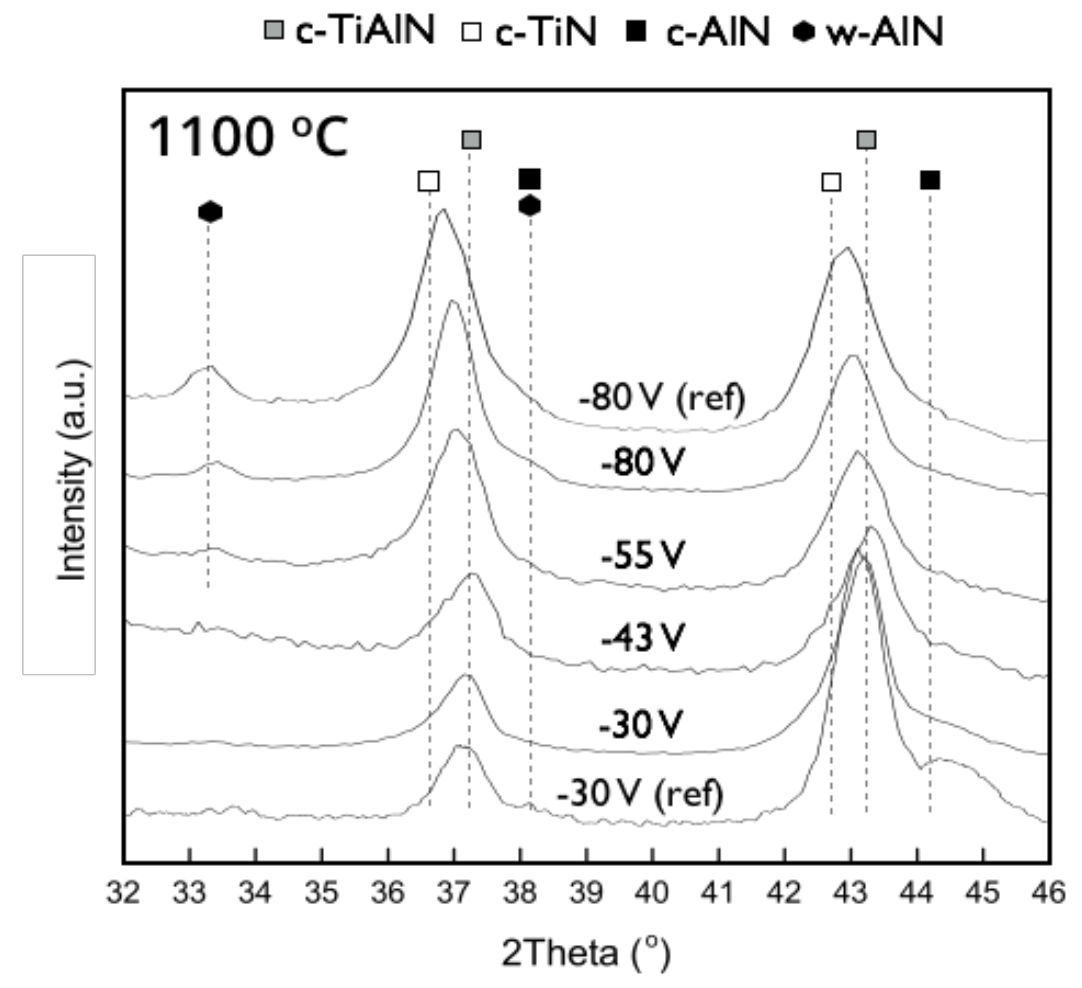

Figure 5. X-ray diffractograms of $\left(\mathrm{Ti}_{0.54} \mathrm{Al}_{0.46}\right) \mathrm{N}_{0.87}$ with bias voltages of $-30 \mathrm{~V},-43 \mathrm{~V},-55$ $\mathrm{V}$, and $-80 \mathrm{~V}$ and reference coatings with bias voltages of $-30 \mathrm{~V}^{15}$ and $-80 \mathrm{~V}$ annealed at $1100{ }^{\circ} \mathrm{C}$.

A more detailed view of the bias voltage effect on the phase transformations of $c$ $\left(\mathrm{Ti}_{0.54} \mathrm{Al}_{0.46}\right) \mathrm{N}_{0.87}$ is shown in Figure 5 at two temperatures, $1100{ }^{\circ} \mathrm{C}$ and $1200{ }^{\circ} \mathrm{C}$. At 1100 ${ }^{\circ} \mathrm{C}$, broadening of $c$-(Ti,Al)N peaks starts to occur for sample $-30 \mathrm{~V}$, wherein the peaks shift to left and small bump occurs to the right. The reference coating biased at $-30 \mathrm{~V}$ heated at this temperature has higher $c$-AlN peak intensity as compared to nitrogen deficient coatings. The w-AlN peaks are only resolved for samples with bias voltage $-55 \mathrm{~V}$ and above, and peaks become more pronounced by increasing the bias. The increase in w-AlN peak intensity with bias voltage is observed in both nitrogen deficient and reference coatings. However, the reference coating has higher $w$-AlN peak intensity as compared to the nitrogen deficient coating signifying that it is in a more advanced decomposed state. 

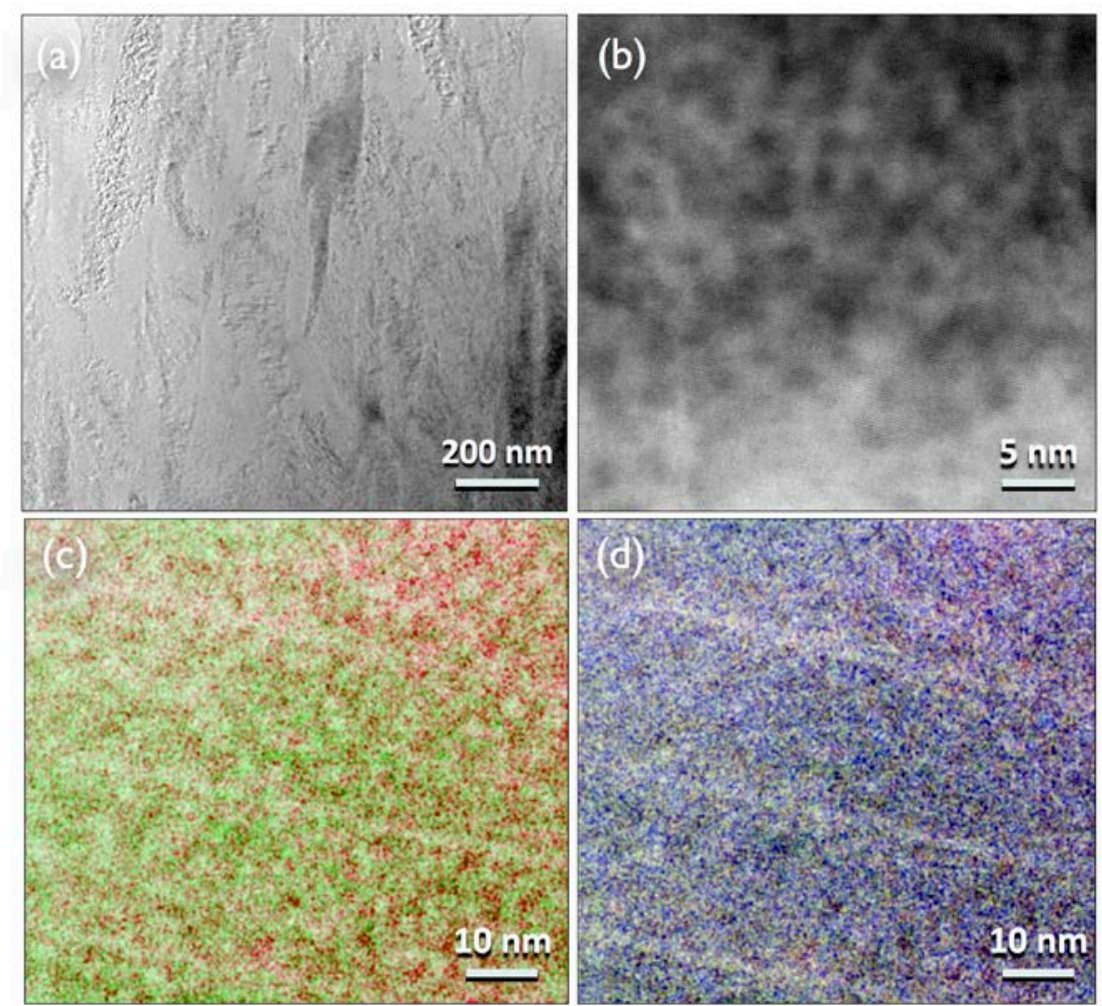

Figure 6. (a) TEM (b) STEM, (c) EFTEM [Ti(red), Al(green)] and (d) EFTEM [Ti(red), $\mathrm{Al}$ (green), $\mathrm{N}$ (blue)] micrographs of $\left(\mathrm{Ti}_{0.54} \mathrm{Al}_{0.46}\right) \mathrm{N}_{0.87}$ grown with a bias voltage of $-55 \mathrm{~V}$ and heated at $900{ }^{\circ} \mathrm{C}$.

The microstructure of $\left(\mathrm{Ti}_{0.54} \mathrm{Al}_{0.46}\right) \mathrm{N}_{0.87}$ coating grown with a bias of $-55 \mathrm{~V}$ and heattreated at $900{ }^{\circ} \mathrm{C}$ is shown in Figure 6a. The STEM micrograph in Figure 6b shows bright and dark contrast, which arises from compositional segregation. The EFTEM images in Figures $6 \mathrm{c}$ and $6 \mathrm{~d}$ confirm segregation on the metal sublattice resulting from the chemical fluctuation during the deposition ${ }^{37}$ while segregation on the N-sublattice cannot be detected. The artificial layers caused by rotating the samples during deposition can also be seen. They arise due to preferential resputtering of the lighter elements. ${ }^{38-39}$ The observed segregation at $900{ }^{\circ} \mathrm{C}$ is less pronounced compared to coatings with stoichiometric N-content, ${ }^{39}$ which indicates a higher phase stability. 


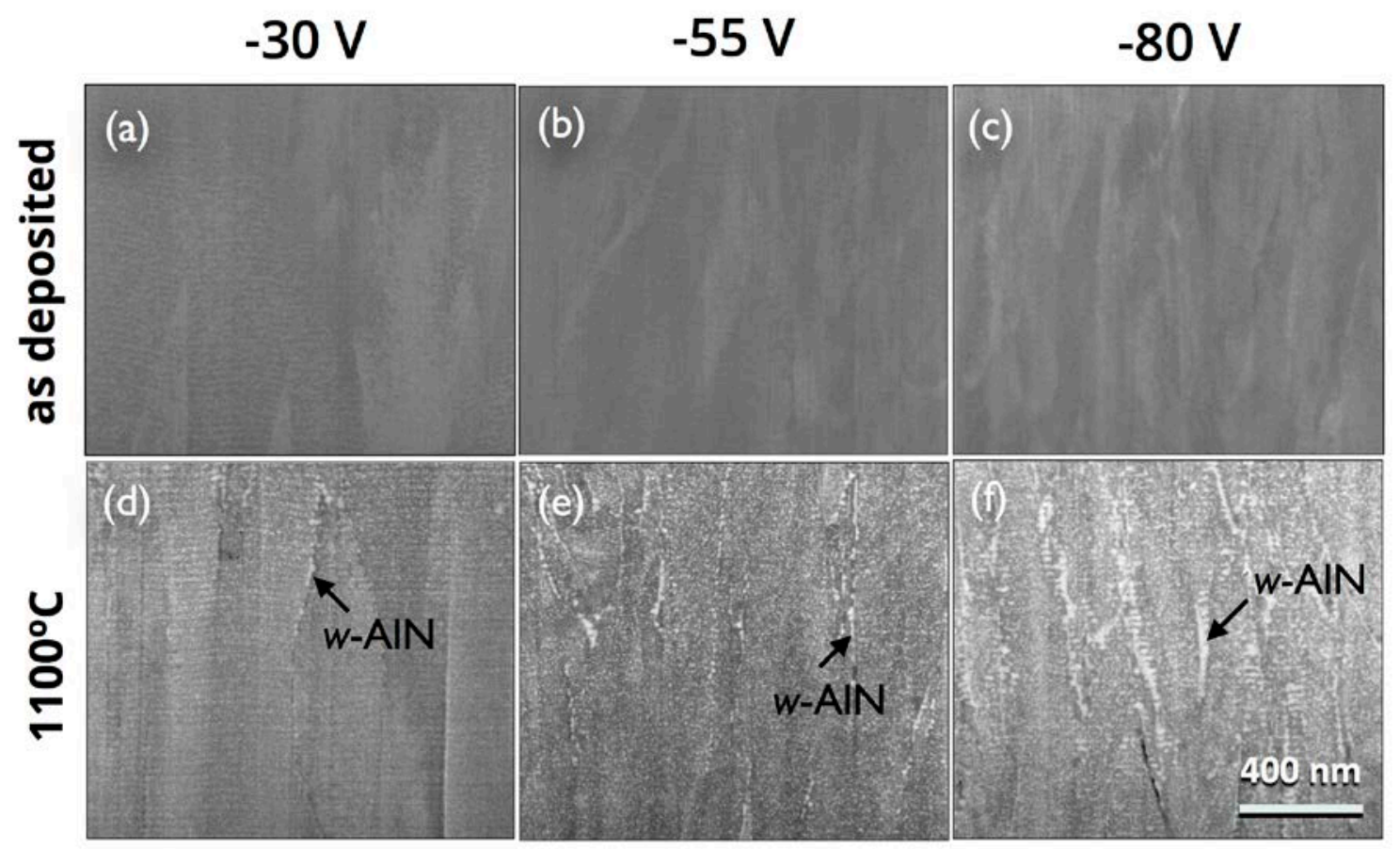

Figure 7. Cross-sectional HRSEM micrographs of $\left(\mathrm{Ti}_{0.54} \mathrm{Al}_{0.46}\right) \mathrm{N}_{0.87}$ in as-deposited state with negative bias voltages of (a) $-30 \mathrm{~V}$, (b) $-55 \mathrm{~V}$, and (c) $-80 \mathrm{~V}$ and heated at $1100{ }^{\circ} \mathrm{C}$ with negative bias voltages of (d) $-30 \mathrm{~V},(\mathrm{e})-55 \mathrm{~V}$, and (f) $-80 \mathrm{~V}$.
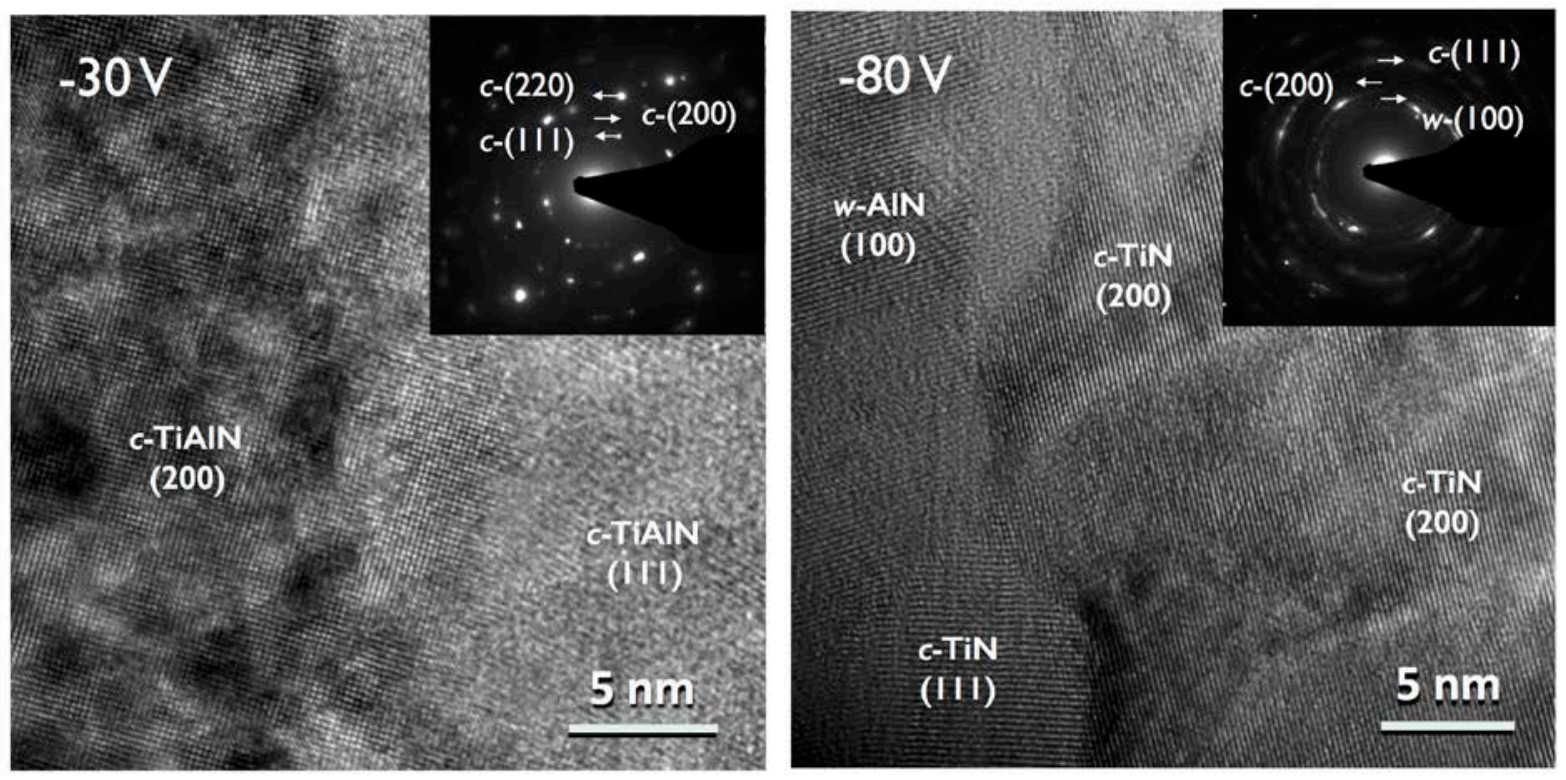

Figure 8. HR-TEM of $\left(\mathrm{Ti}_{0.54} \mathrm{Al}_{0.46}\right) \mathrm{N}_{0.87}$ heated at $1100{ }^{\circ} \mathrm{C}$ and biased at (a) $-30 \mathrm{~V}$ and (b) -80 $\mathrm{V}$ and SAED of (c) $-30 \mathrm{~V}$ and (d) $-80 \mathrm{~V}$.

Figure 7 shows the cross sectional SEM micrographs of the samples biased at -30 V, $55 \mathrm{~V}$, and $-80 \mathrm{~V}$ then post-annealed at $1100{ }^{\circ} \mathrm{C}$, i.e. the critical temperature where $w$-AlN were observed in some samples from the XRD result. It can be observed that large w-AlN 
domains are growing mainly at grain boundaries. Sample biased at $-80 \mathrm{~V}$ presents a higher amount of grain boundaries in comparison to the lower biased samples. Therefore, it is expected that highly biased samples have a larger volume fraction of $w$-AlN, as also observed from the XRD result. The high-resolution TEM images of samples biased at $-30 \mathrm{~V}$ and $-80 \mathrm{~V}$ and their corresponding SAED patterns are shown in Figure 8. When the coatings are heated at $1100{ }^{\circ} \mathrm{C}$, the sample biased at $-30 \mathrm{~V}$ retains its $c-(\mathrm{Ti}, \mathrm{Al}) \mathrm{N}$ structure while the $-80 \mathrm{~V}$ sample has segregated to $c$-TiN and $w$-AlN.

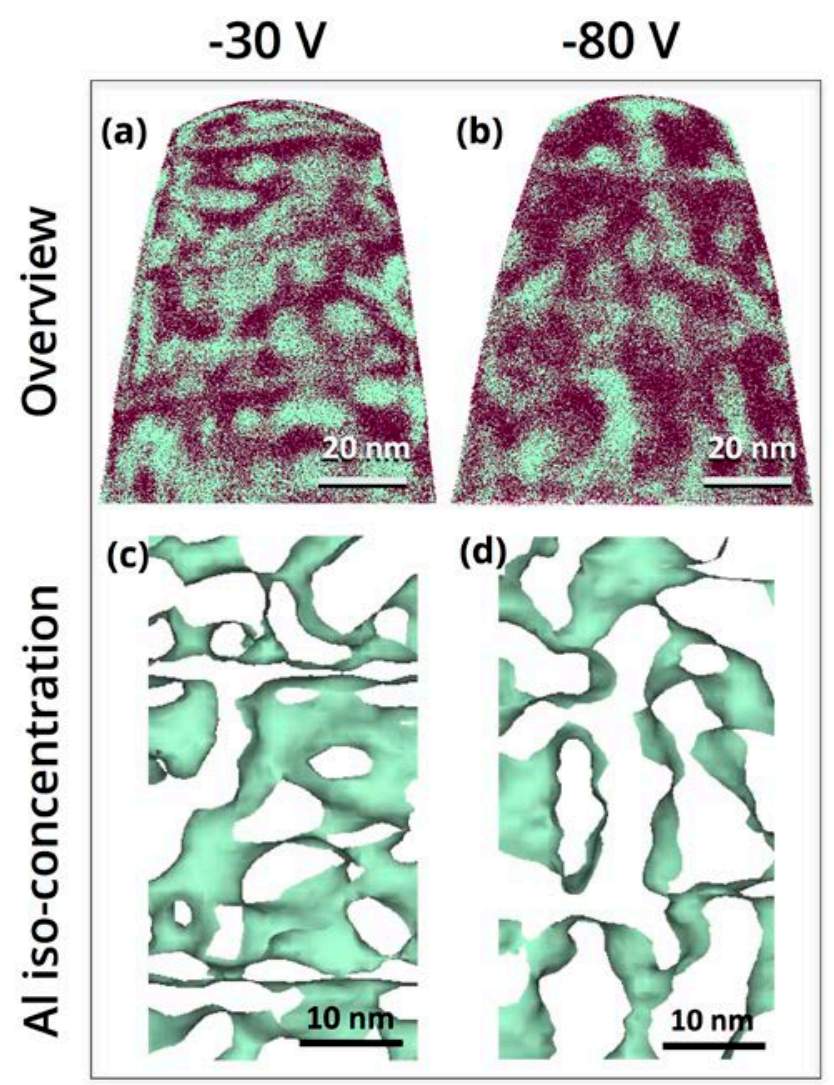

Figure 9. Overview of the 3D reconstructed tip [Ti(red), $\mathrm{Al}$ (green)] of $\left(\mathrm{Ti}_{0.54} \mathrm{Al}_{0.46}\right) \mathrm{N}_{0.87}$ films annealed at $1100{ }^{\circ} \mathrm{C}$ with bias voltage of (a) $-30 \mathrm{~V}$ and (b) $-80 \mathrm{~V}$ and the $\mathrm{Al}$ isoconcentration surfaces for (c) $-30 \mathrm{~V}$ and (d) $-80 \mathrm{~V}$.

3D-APT data from $\left(\mathrm{Ti}_{0.54} \mathrm{Al}_{0.46}\right) \mathrm{N}_{0.87}$ coatings biased at $-30 \mathrm{~V}$ and $-80 \mathrm{~V}$ and annealed at $1100{ }^{\circ} \mathrm{C}$ are presented in Figure 9. Figure 9(a) and (b) show elemental contrast overviews of the reconstructed tips. For clarity only $\mathrm{Al}$ and Ti elements are shown. The morphology of the segregated aluminum- and titanium-rich domains is displayed in Figure 9(c) and (d), 
where aluminum iso-concentration surfaces were drawn for the same reconstructed tips at an $\mathrm{Al}$ value of 26 at. \%. Both biased samples presented a 3D interconnected segregation network. For the sample biased at $-30 \mathrm{~V}$, the domains are rounded while at $-80 \mathrm{~V}$ the domains are slightly elongated. The segregated domains of the reference coatings have similar morphology as the nitrogen deficient coatings (figure not shown). There is no significant difference of the size of the domains between coatings with different $\mathrm{N}$-stoichiometry and applied negative bias. The composition profiles across the interfaces of the decomposed Aland Ti-rich domains were obtained by using proximity concentration histogram perpendicular to the surface as described by Gault et al. ${ }^{40}$ Elemental composition of the samples annealed at $1100{ }^{\circ} \mathrm{C}$ is obtained from the concentration profiles across the Al-rich and Ti-rich clusters. Table 2 shows that the composition of the domains for the two samples. The composition of the domains is similar in the two samples.

Table II. Elemental composition inside Ti- and Al-rich domains of $\left(\mathrm{Ti}_{0.54} \mathrm{Al}_{0.46}\right) \mathrm{N}_{0.87}$ films biased at $-30 \mathrm{~V}$ and $-80 \mathrm{~V}$ annealed at $1100{ }^{\circ} \mathrm{C}$.

\begin{tabular}{|c|c|c|c|}
\hline Bias Voltage & $\mathrm{Al}$ (at. \%) & $\mathrm{Ti}$ (at. \%) & $\mathrm{N}$ (at. \%) \\
\hline -30 V (Al-rich) & $50.9 \pm 0.4$ & $2.2 \pm 0.1$ & $46.7 \pm 0.4$ \\
\hline -80 V (Al-rich) & $48.3 \pm 0.4$ & $4.4 \pm 0.2$ & $46.8 \pm 0.4$ \\
\hline$-30 \mathrm{~V}$ (Ti-rich) & $3.3 \pm 0.1$ & $48.2 \pm 0.3$ & $48.2 \pm 0.3$ \\
\hline$-80 \mathrm{~V}$ (Ti-rich) & $4.5 \pm 0.1$ & $46.2 \pm 0.3$ & $48.9 \pm 0.3$ \\
\hline
\end{tabular}

The hardness evolution of the biased $\left(\mathrm{Ti}_{0.54} \mathrm{Al}_{0.46}\right) \mathrm{N}_{0.87}$ films as a function of annealing temperature is shown in Figure 10. For the as-deposited state, the hardness increases with applied negative bias voltage. The hardness values of the films are retained until $800{ }^{\circ} \mathrm{C}$. Age hardening is observed for all samples when annealed above this temperature. The occurrence of hardness enhancement has been prolonged when the coatings have lesser bias. A significant drop in hardness is observed when the samples are further 
annealed to higher temperatures. The hardness drops at $1200^{\circ} \mathrm{C}$ for the low biased samples ($30 \mathrm{~V}$ and $-55 \mathrm{~V})$ while the more highly biased sample $(-80 \mathrm{~V})$ decreases at $1000{ }^{\circ} \mathrm{C}$. The indentation results show that the sample with the lowest bias had the most prolonged age hardening. The reference coating biased at $-30 \mathrm{~V}$ has hardness value comparable to the nitrogen deficient $\left(\mathrm{Ti}_{0.54} \mathrm{Al}_{0.46}\right) \mathrm{N}_{0.87}$ in the as-deposited state; however, the former exhibits age hardening at lower temperature of around $800{ }^{\circ} \mathrm{C}$ and its hardness started to drop at 900 ${ }^{\circ} \mathrm{C}$. The $\left(\mathrm{Ti}_{0.54} \mathrm{Al}_{0.46}\right) \mathrm{N}_{0.87}$ coating biased at $-55 \mathrm{~V}$ showed the optimal mechanical behavior since the hardness values are relatively high and age hardening occurred at higher temperature and retained for a longer temperature range.

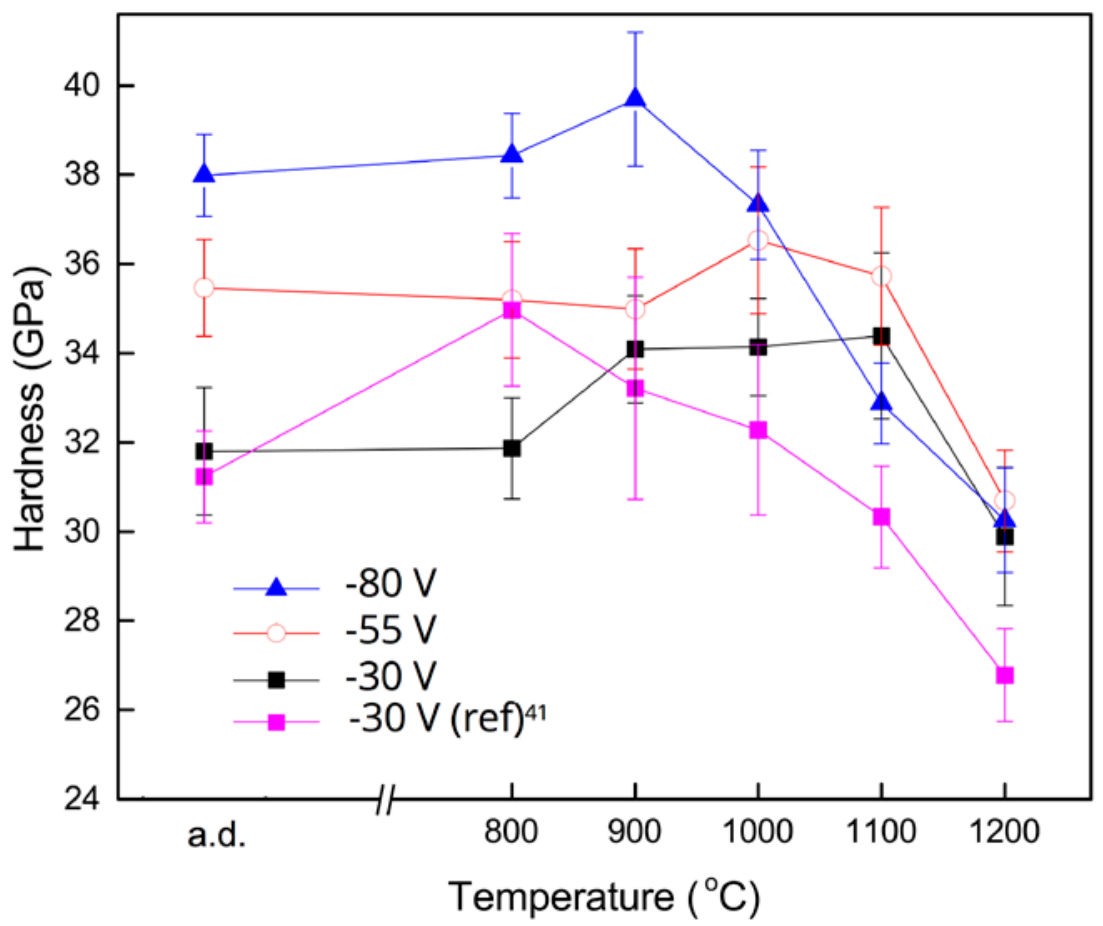

Figure 10. Hardness at different temperatures of $\left(\mathrm{Ti}_{0.54} \mathrm{Al}_{0.46}\right) \mathrm{N}_{0.87}$ films biased at $-30 \mathrm{~V},-55$ $\mathrm{V}$, and $-80 \mathrm{~V}$ and the reference sample ${ }^{41}$.

\section{DISCUSSION}

Previous studies have shown that the presence of nitrogen vacancies significantly improves the phase stability of (Ti,Al)N-alloys, in which spinodal decomposition is retarded and $w$-AlN formation is shifted to higher temperatures. ${ }^{14-15}$ These results suggest defect engineering as a route for new and improved materials. However, the synthesis method used 
may affect the defect structure. It has been reported that cathodic arc deposition introduces self-interstitials and anti-sites in the film ${ }^{25}$ and one key deposition parameter affecting such point defect generation is the substrate bias voltage. ${ }^{23,25}$ In this study, we build on the concept of vacancy improved thermal stability and include the effect of point defects generated during growth. We kept other parameters constant to isolate the effect of bias voltage, which included a constant coating composition. We will divide the discussion of our findings in three parts: address the effect of bias voltage on the growth of nitrogen deficient (Ti,Al)N, discuss how it affects the coatings' thermal stability, and describe the effect of microstructural evolution on their mechanical properties.

\section{A. Microstructure of as-deposited films}

The microstructure of nitrogen deficient $(\mathrm{Ti}, \mathrm{Al}) \mathrm{N}$ coatings is significantly affected when the growth-conditions are altered by changing the bias voltage. When applying a negative bias voltage to the substrate during arc deposition positively charged metal ions are attracted towards the growing film surface, wherein additional kinetic energy and momentum transfer change the film forming conditions. This alters the morphology and grain size of the films because energetic ions directly associated with high bias voltage enhance surface diffusion, recrystallization, and resputtering. ${ }^{42-43}$ The $\left(\mathrm{Ti}_{0.54} \mathrm{Al}_{0.46}\right) \mathrm{N}_{0.87}$ coatings grown with higher bias voltage results in finer columnar structure since enhanced energy of incoming ions generates more point defects, which increases the nucleation rates and defect density of the coatings during growth. ${ }^{44}$ When the defect density is high, the local epitaxial growth of individual columns is interrupted by the occurrence of repeated nucleation. ${ }^{45-46}$

As-deposited $\left(\mathrm{Ti}_{0.54} \mathrm{Al}_{0.46}\right) \mathrm{N}_{\mathrm{y}}$ coatings grown at different bias voltages all show single-phase solid solution NaCl-structure. The correlation of the peak intensity ratio and applied negative bias voltage from the XRD results is due to a change in crystallographic texture and not an alteration of the films' stoichiometry. The change in preferred orientation 
from (001) to (111) and (110) by increasing the bias is a consequence of increasing ion bombardment. In general, the lowest overall energy condition resulting from the competition of surface energy, strain energy and stopping energy of different lattice planes determines the preferred orientation of a multi-component fcc crystal with NaCl-type structure. ${ }^{47-48}$ High bombardment energy of incoming and adsorbed spices would favor (111) and (110) growth, which have the lowest strain energy and lowest stopping energy, respectively. The preference of (110) is also attributed to an ion channeling effect, ${ }^{49}$ in which the planes with lower resputtering rate becomes dominant since they survive the high ion bombardment best.

The cathodic arc deposition technique involves bombardment of high energetic ions during the film growth and thus the intrinsic stress of the coatings can be very high. Compressive residual stresses are generated when the number of atoms per unit volume of the film increases through implantation of incoming ions without any atomic rearrangement. ${ }^{50}$ For $(\mathrm{Ti}, \mathrm{Al}) \mathrm{N}$, residual stresses are mainly caused by interstitials and antisites (occupation of metal ions or atoms on the lattice sites of nitrogen and nitrogen on the metal lattice sites), which increase the compressive strain fields of the surrounding lattice. ${ }^{25}$ The anti-site and interstitial defect concentrations increase with bias voltage or the energy of the incoming ions because it enhances the collision cascade. Consequently, applying a high bias voltage increases the strain energy stored in the system ${ }^{51}$ and may affect the diffusion kinetics and evolution of the microstructure when exposed to high temperature. The films deposited with a high applied bias of $-80 \mathrm{~V}$ have the highest compressive residual stress, which causes the interplanar distances parallel and perpendicular to the growth direction to differ. $^{42}$ Dispersion of the lattice parameter can result in considerable changes in the activation of processes such as vacancy and interstitial migration when the coatings are subjected to different temperatures. In section $\mathrm{B}$, the role of point defects on the observed 
changes during annealing will be discussed with respect to the thermal stability of nitrogen deficient (Ti,Al)N.

\section{B. Thermal Stability of $\mathrm{Ti}_{1-\mathrm{x}} \mathrm{Al}_{\mathrm{x}} \mathrm{N}_{\mathrm{y}}$}

Nitrogen deficient $\left(\mathrm{Ti}_{0.54} \mathrm{Al}_{0.46}\right) \mathrm{N}_{0.87}$ coatings have shown enhanced phase stability, wherein phase transformation from $c$-AlN to $w$-AlN occurs at higher temperatures as compared to the same transition in stoichiometric films. ${ }^{16-17,19,52-53}$ For $\left(\mathrm{Ti}_{0.54} \mathrm{Al}_{0.46}\right) \mathrm{N}_{\mathrm{y}}$ where $\mathrm{y}<1, a b$ initio calculations indicate that nitrogen vacancies is the fundamental reason for the lack of nitrogen in the coatings. ${ }^{54}$ The delayed phase transformation to $w$-AlN of these coatings is mainly attributed to the reduction of mixing enthalpy and the alteration of the phonon dispersion in the presence of nitrogen vacancies. ${ }^{15}$ It is expected that the miscibility gap is reduced when nitrogen vacancies are present and as a consequence, the spinodal line is suppressed to lower temperatures.

Stress relaxation and phase transformation occur when the coatings are subjected to increasing temperatures as indicated by the heat flow responses of the DSC curve. A system under such condition seeks to minimize its total energy during which atoms tend to rearrange into configuration giving lower stress provided that they have sufficient time and mobility. The relaxation is attained through migration, redistribution, and annihilation of stressgenerating lattice defects. ${ }^{23,55}$ The primary defects present in $(\mathrm{Ti}, \mathrm{Al}) \mathrm{N}$ coatings annealed above their deposition temperature are the less mobile point defects, which are the metal interstitials and vacancies. ${ }^{55}$ Nitrogen interstitials have low activation energy and thus they easily migrate through diffusion to nitrogen vacancies, inner boundaries, or to the surface when annealed at low temperatures $\left(<500{ }^{\circ} \mathrm{C}\right) .{ }^{56}$ Metal and nitrogen vacancies affect significantly the thermal stability of TiAlN, but in different ways. The low onset temperature for spinodal decomposition of overstoichiometric ( $\mathrm{Ti}, \mathrm{Al}) \mathrm{N}_{\mathrm{y}}$ is attributed to their existing metal vacancies, which enhance diffusion on the metal sublattice. ${ }^{18}$ Diffusion requires energy 
to overcome the energy barriers for vacancy formation and changing atomic positions. Decomposition is then favored in the presence of metal vacancies because only the activation energy for changing atomic positions is needed. In $\left(\mathrm{Ti}_{0.54} \mathrm{Al}_{0.46}\right) \mathrm{N}_{0.87}$, nitrogen vacancies are prevalent in the system rather than metal vacancies. The presence of nitrogen vacancies in the $\left(\mathrm{Ti}_{0.54} \mathrm{Al}_{0.46}\right) \mathrm{N}_{0.87}$ material system may also allow diffusion of substitutional metal atoms such that temporary anti-site occupation occurs. However, the formation of anti-lattice sites is associated with high-energy barriers and actually less likely to occur. Nitrogen vacancies also have high activation energy for migration and exhibits slight repulsion, which delays decomposition. ${ }^{15,56}$ Thus, nitrogen vacancy concentration in $\left(\mathrm{Ti}_{0.54} \mathrm{Al}_{0.46}\right) \mathrm{N}_{0.87}$ would contribute to the thermal stability enhancement of in contrast to metal vacancies.

In-situ XRD diffraction study on $\mathrm{Ti}_{0.5} \mathrm{Al}_{0.5} \mathrm{~N}$ coatings has shown that increasing the negative bias voltage delays the lattice strain reduction resulting to an accelerated phase decomposition of the material, i.e. $w$-AlN formation already occurs at $850{ }^{\circ} \mathrm{C} .{ }^{16}$ Strain reduction happens when the inherent structural defects undergo thermally activated rearrangement and then annihilated or migrate to lower energy sites. The larger size of $\mathrm{T}_{1}$ peak from the DSC curve of the $\left(\mathrm{Ti}_{0.54} \mathrm{Al}_{0.46}\right) \mathrm{N}_{0.87}$ coatings biased at $-30 \mathrm{~V}$ as compared to the coatings biased at $-80 \mathrm{~V}$ indicates that many point defects were already annihilated at lower temperatures at lower biasing condition. This signifies that the defects caused by high ion energy bombardment in the presence of $\mathrm{N}$ vacancies, are more stable than at low energy bombardment, ${ }^{57-58}$ opposite to Rogström et al. $^{8}$ observations for the stoichiometric case $\left(\operatorname{Ti}_{0.35} \mathrm{Al}_{0.65}\right)$ N. Perhaps by forming more complex defect structures that are more stable. The film biased at $-80 \mathrm{~V}$ has delayed the lattice strain reduction to higher temperature, thus there are considerable amount of defects that cause the internal energy of the system to increase and consequently accelerates the decomposition tendencies of $c$-(Ti,Al)N to its most stable form, i.e $c$-TiN and $w$-AlN. 
Koller et al. ${ }^{59}$ have presented the idea that microstructure affects the phase separation of the thin film coatings. It was suggested that under-dense column boundaries caused by lowly biased coatings accelerates decomposition because they provide higher diffusion and reduce retarding forces against volume changes. In this study, the applied negative bias voltage was increased to obtain more dense films. However, the high biased coatings have shown to exhibit decomposition at earlier temperature. In-situ x-ray scattering studies have indicated that the size of the Al-rich domains also affects the transformation rate of $c$-AlN to $w$-AlN in $\mathrm{Ti}_{1-\mathrm{x}} \mathrm{Al}_{\mathrm{x}} \mathrm{N}$. ${ }^{8,12}$ In the case of $\left(\mathrm{Ti}_{0.54} \mathrm{Al}_{0.46}\right) \mathrm{N}_{0.87}$, the size of the Al-rich domains of both low and high biased films is similar, but the later has shown earlier transformation of $c$ AlN to $w$-AlN. Thus, the accelerated decomposition of the highly biased nitrogen deficient (Ti,Al)N is not attributed to the grain density nor domain size changes.

\section{Mechanical Properties}

In this study, defects and residual stresses have been shown to be beneficial to the film's physical properties (e.g. high hardness) in the as-deposited state. The high grain boundary density, high residual stress, and reduction of crystallite size of the $\left(\mathrm{Ti}_{0.54} \mathrm{Al}_{0.46}\right) \mathrm{N}_{0.87}$ film biased at $-80 \mathrm{~V}$ contribute to its higher as-deposited hardness value as compared to film biased at $-30 \mathrm{~V}$. A significant increase in hardness is observed when the coatings are subjected to high temperatures. The age hardening observed for the coatings are due to the changes in the microstructure caused by spinodal deposition of $c$-(Ti,Al)N into coherent $c$-TiN and $c$-AlN domains. This mechanism creates composition fluctuation and differences in elastic properties, which prevents dislocations to propagate and thus resists plastic deformation, ${ }^{7,36,53}$ known as coherency and Kohler hardening. ${ }^{10,60}$

Further annealing to higher temperatures causes the transformation of c-AlN to $w$ AlN. This transformation is detrimental to the film's mechanical properties as it causes the hardness values to significantly drop. The high rate of phase transformation of the coatings 
biased at $-80 \mathrm{~V}$ is attributed to their high density of grain and column boundaries, which serve as high diffusion paths. ${ }^{17}$ The grain size modification of the thin films induced by biasing may play lesser role on their spinodal decomposition; however, it has a considerable effect on other phenomena, such as nucleation. The formation of $w$-AlN at grain boundaries is enhanced when the decomposition is suppressed inside the grains. ${ }^{15,61}$ The phase transformation would cause an increase in unit cell volume up to around $20 \%$, which

obliterates the coherency and increase the likelihood of dislocation movements. ${ }^{36}$ It is essential to observe that the critical temperatures for the hardness drop vary with bias voltage. The low biased samples had hardness drop at higher temperatures, which signifies higher phase stability since they have prolonged age hardening effect of the (Ti,Al)N system.

\section{CONCLUSIONS}

The microstructure and thermal stability of nitrogen deficient $\left(\mathrm{Ti}_{0.54} \mathrm{Al}_{0.46}\right) \mathrm{N}_{0.87}$ films with different applied bias voltage were investigated. In the as-deposited state, the highly biased film showed improvements in hardness, morphology, and microstructure because of the enhanced ion bombardment that caused high compressive stresses and densification. At elevated temperature, this ternary material with nitrogen vacancies has shown high thermal stability, in which the phase transformation of c-AlN to w-AlN is suspended to higher temperatures compared to reference samples with compositions close to stoichiometric value. Adding the factor of bias voltage to the nitrogen deficient film has influenced the thermal stability of the material in addition to nitrogen vacancies. The highly biased films have enhanced the driving force for phase separation because of the delayed annihilation of point defects at high temperature, resulting to an increase in internal energy of the system. The low biased film has delayed phase transformation to $w$-AlN thus improving the mechanical properties of the coatings, i.e. age hardening effect has been prolonged to the highest reported temperature. Point defect concentration generated during deposition plays a critical role in 
designing (Ti,Al)N films with desired thermal stability and mechanical properties suitable for hard coating applications.

\section{ACKNOWLEDGMENTS}

The work was supported by the European Union's Erasmus Mundus doctoral program in Materials Science and Engineering (DocMASE), the Swedish Research Council (grant no 621-2012-4401), the Swedish government strategic research area grant AFM - SFO MatLiU (2009-00971) and VINNOVA (M - Era.net project MC2 grant no. 2013-02355). The atom probe was financed by the DFG and the federal state government of Saarland (INST 256/2981 FUGG). Funding for FIB/SEM instrument was granted by the European Regional Development Fund (Project AME-Lab C/4-EFRE-13/2009/Br).

\section{REFERENCES}

${ }^{1}$ J. E. Sundgren and H. Hentzell, J. Vac. Sci. Technol., A 4, 2259 (1986).

${ }^{2}$ P. Jindal, A. Santhanam, U. Schleinkofer, and A. Shuster, Int. J. Refract. Met. Hard Mater. 17, 163 (1999).

${ }^{3}$ J. Musil, Surf. Coat. Technol. 125, 322 (2000).

${ }^{4}$ S. PalDey and S. Deevi, Mater. Sci. Eng., A 342, 58 (2003).

${ }^{5}$ N. Shulumba, O. Hellman, Z. Raza, B. Alling, J. Barrirero, F. Mücklich, I. A. Abrikosov, and M. Odén, Phys. Rev. Lett. 117, 205502 (2016).

${ }^{6}$ M. Oden, L. Rogström, A. Knutsson, M. Terner, P. Hedström, J. Almer, and J. Ilavsky, Appl. Phys. Lett. 94, 053114 (2009).

${ }^{7}$ A. Hörling, L. Hultman, M. Odén, J. Sjölén, and L. Karlsson, Surf. Coat. Technol. 191, 384 (2005).

${ }^{8}$ L. Rogström, J. Ullbrand, J. Almer, L. Hultman, B. Jansson, and M. Odén, Thin Solid Films 520, 5542 (2012).

${ }^{9}$ F. Wang, I. A. Abrikosov, S. I. Simak, M. Odén, F. Mücklich, and F. Tasnádi, Phys. Rev. B 93, 174201 (2016).

${ }^{10}$ F. Tasnádi, I. A. Abrikosov, L. Rogström, J. Almer, M. P. Johansson, and M. Odén, Appl. Phys. Lett. 97, 231902 (2010).

${ }^{11}$ N. Shulumba, O. Hellman, L. Rogström, Z. Raza, F. Tasnádi, I. A. Abrikosov, and M. Odén, Appl. Phys. Lett. 107, 231901 (2015).

${ }^{12}$ N. Norrby, L. Rogström, M. P. Johansson-Jõesaar, N. Schell, and M. Odén, Acta Mater. 73, 205 (2014).

${ }^{13}$ P. H. Mayrhofer, A. Hörling, L. Karlsson, J. Sjölén, T. Larsson, C. Mitterer, and L. Hultman, Appl. Phys. Lett. 83, 2049 (2003).

${ }^{14}$ B. Alling, A. Karimi, L. Hultman, and I. A. Abrikosov, Appl. Phys. Lett. 92, 071903 (2008). 
${ }^{15}$ I. C. Schramm, M. P. Johansson Jõesaar, J. Jensen, F. Mücklich, and M. Odén, Acta Mater. 119, 218 (2016).

${ }^{16}$ C. Wüstefeld, D. Rafaja, M. Dopita, M. Motylenko, C. Baehtz, C. Michotte, and M. Kathrein, Surf. Coat. Technol. 206, 1727 (2011).

${ }^{17}$ R. Rachbauer, S. Massl, E. Stergar, D. Holec, D. Kiener, J. Keckes, J. Patscheider, M. Stiefel, H. Leitner, and P. Mayrhofer, J. Appl. Phys. 110, 023515 (2011).

${ }^{18}$ M. to Baben, M. Hans, D. Primetzhofer, S. Evertz, H. Ruess, and J. M. Schneider, Mater. Res. Lett. 5, 158 (2017).

${ }^{19}$ F. Rovere, D. Music, S. Ershov, H.-G. Fuss, P. H. Mayrhofer, and J. M. Schneider, J. Phys. D: Appl. Phys. 43, 035302 (2010).

${ }^{20} \mathrm{P}$. H. Mayrhofer, F. D. Fischer, H. J. Böhm, C. Mitterer, and J. M. Schneider, Acta Mater. 55, 1441 (2007).

${ }^{21}$ M. Pfeiler, K. Kutschej, M. Penoy, C. Michotte, C. Mitterer, and M. Kathrein, Surf. Coat. Technol. 202, 1050 (2007).

${ }^{22}$ H. Ljungcrantz, L. Hultman, J. E. Sundgren, and L. Karlsson, J. Appl. Phys. 78, 832 (1995).

${ }^{23}$ M. Ahlgren and H. Blomqvist, Surf. Coat. Technol. 200, 157 (2005).

${ }^{24}$ A. Anders, Appl. Phys. Lett. 80, 1100 (2002).

${ }^{25}$ H. Oettel, R. Wiedemann, and S. Preißler, Surf. Coat. Technol. 74, 273 (1995).

${ }^{26}$ N. Norrby, H. Lind, G. Parakhonskiy, M. P. Johansson, F. Tasnádi, L. S. Dubrovinsky, N. Dubrovinskaia, I. A. Abrikosov, and M. Odén, J. Appl. Phys. 113, 053515 (2013).

${ }^{27}$ D. R. Kingham, Surf. Sci. 116, 273 (1982).

${ }^{28}$ K. Thompson, D. Lawrence, D. J. Larson, J. D. Olson, T. F. Kelly, and B. Gorman, Ultramicroscopy 107, 131 (2007).

${ }^{29}$ W. C. Oliver and G. M. Pharr, Journal of Materials Research 7, 1564 (2011).

${ }^{30}$ B. D. Cullity, S. R. Cullity, and S. Stock, Elements of X-ray Diffraction (Prentice Hall, NewJersey, 2001).

${ }^{31}$ C. Wüstefeld, D. Rafaja, V. Klemm, C. Michotte, and M. Kathrein, Surf. Coat. Technol. 205, 1345 (2010).

${ }^{32}$ N. Norrby, M. P. Johansson-Jõesaar, and M. Odén, Surf. Coat. Technol. 257, 102 (2014).

${ }^{33}$ O. Piot, C. Gautier, and J. Machet, Surf. Coat. Technol. 94, 409 (1997).

${ }^{34}$ A. Knutsson, M. Johansson, L. Karlsson, and M. Odén, J. Appl. Phys. 108, 044312 (2010).

${ }^{35}$ P. H. Mayrhofer, C. Mitterer, L. Hultman, and H. Clemens, Prog. Mater Sci. 51, 1032 (2006).

${ }^{36}$ I. A. Abrikosov, A. Knutsson, B. Alling, F. Tasnádi, H. Lind, L. Hultman, and M. Odén, Materials 4, 1599 (2011).

${ }^{37}$ L. J. S. Johnson, M. Thuvander, K. Stiller, M. Odén, and L. Hultman, Thin Solid Films 520, 4362 (2012).

${ }^{38}$ A. O. Eriksson, J. Q. Zhu, N. Ghafoor, M. P. Johansson, J. Sjölen, J. Jensen, M. Odén, L. Hultman, and J. Rosén, Surf. Coat. Technol. 205, 3923 (2011).

${ }^{39}$ A. Knutsson, J. Ullbrand, L. Rogström, N. Norrby, L. Johnson, L. Hultman, J. Almer, M. J. Jöesaar, B. Jansson, and M. Odén, J. Appl. Phys. 113, 213518 (2013).

${ }^{40}$ B. Gault, M. P. Moody, J. M. Cairney, and S. P. Ringer, Atom probe microscopy, Vol. 160 (Springer Science \& Business Media, 2012).

${ }^{41}$ I. C. Schramm, C. Pauly, M. P. Johansson Jõesaar, S. Suarez, F. Mücklich, and M. Odén, Effects of $\mathrm{N}$ vacancies on phase stability and mechanical properties of arc deposited (Ti0.52Al0.48)Ny (submitted).

${ }^{42}$ S. M. Rossnagel and J. J. Cuomo, Vacuum 38, 73 (1988).

${ }^{43}$ A. Raveh, I. Zukerman, R. Shneck, R. Avni, and I. Fried, Surf. Coat. Technol. 201, 6136 (2007).

44J. Almer, M. Odén, L. Hultman, and G. Håkansson, J. Vac. Sci. Technol., A 18, 121 (2000). 
${ }^{45}$ I. Petrov, P. Barna, L. Hultman, and J. Greene, J. Vac. Sci. Technol., A 21, S117 (2003).

${ }^{46}$ I. Petrov, L. Hultman, J. E. Sundgren, and J. Greene, J. Vac. Sci. Technol., A 10, 265 (1992).

${ }^{47}$ J. Zhao, X. Wang, Z. Chen, S. Yang, T. Shi, and X. Liu, J. Phys. D: Appl. Phys. 30, 5 (1997).

${ }^{48}$ J. Pelleg, L. Z. Zevin, S. Lungo, and N. Croitoru, Thin Solid Films 197, 117 (1991).

${ }^{49}$ L. S. Yu, J. M. Harper, J. J. Cuomo, and D. A. Smith, J. Vac. Sci. Technol., A 4, 443 (1986).

${ }^{50}$ M. M. M. Bilek, D. R. McKenzie, and W. Moeller, Surf. Coat. Technol. 186, 21 (2004).

${ }^{51}$ D. Rafaja, C. Wüstefeld, C. Baehtz, V. Klemm, M. Dopita, M. Motylenko, C. Michotte, and M. Kathrein, Metall. Mater. Trans. A 42, 559 (2011).

${ }^{52}$ P. H. Mayrhofer, C. Mitterer, and H. Clemens, Adv. Eng. Mater. 7, 1071 (2005).

${ }^{53}$ A. Hörling, L. Hultman, M. Odén, J. Sjölén, and L. Karlsson, J. Vac. Sci. Technol., A 20, 1815 (2002).

${ }^{54}$ M. to Baben, L. Raumann, D. Music, and J. M. Schneider, J Phys-Condens Mat 24, 155401 (2012).

${ }^{55}$ L. Hultman, Vacuum 57, 1 (2000).

${ }^{56}$ L. Tsetseris, N. Kalfagiannis, S. Logothetidis, and S. T. Pantelides, Phys. Rev. Lett. 99, 125503 (2007).

${ }^{57}$ L. Karlsson, A. Hörling, M. P. Johansson, L. Hultman, and G. Ramanath, Acta Mater. 50, 5103 (2002).

${ }^{58}$ P. H. Mayrhofer and C. Mitterer, Surf. Coat. Technol. 133-134, 131 (2000).

${ }^{59}$ C. M. Koller, R. Hollerweger, C. Sabitzer, R. Rachbauer, S. Kolozsvari, J. Paulitsch, and P. H. Mayrhofer, Surf. Coat. Technol. 259, 599 (2014).

${ }^{60}$ J. S. Koehler, Phys. Rev. B 2, 547 (1970).

${ }^{61}$ R. Forsén, M. P. Johansson, M. Odén, and N. Ghafoor, Thin Solid Films 534, 394 (2013). 